\title{
The Diversity Management Approach to Equal Employment in Australian Organisations
}

\section{J. Burgess * \\ E. French ** \\ G. Strachan ***}

\begin{abstract}
This article assesses the 'Managing Diversity' (MD) approach in Australia, examining its drivers, discussing its relationship to legislation designed to promote equity, and examining it as a set of management practices. It has been plausibly argued, on efficiency grounds, that responsibility for achieving equality objectives must be shifted to organisations as this links contextual conditions to organisational processes. However, even where there is some prescription and guidance such as that provided by Australian Equal Employment Opportunity (EEO) legislation targeted specifically to women employees, both practice and outcomes are variable. This is even more the case with MD where there are no guiding principles or legislative support. The article examines the best practice EEO and MD programs of Australian organisations to demonstrate the approaches and programs that are being developed at the workplace and to highlight the limitations of the 'business case' approach underlying such programs.
\end{abstract}

\section{Introduction}

Australia has a mosaic of anti discrimination and equal employment opportunity (EEO) laws covering the workplace, designed to provide protection against direct and indirect discrimination for such groups as women, the disabled, older employees and gays and lesbians, as well as other legislation designed to promote career opportunities for women. These legislative requirements are in turn supported through industrial agreements, and through organisational policies. Often the resulting policies and programs within organisations proclaim workforce diversity as an asset, and are based on the claim that diversity can be harnessed towards organisational objectives. Thus increasingly workplace equity programs have been brought under the broad label of managing diversity (MD). Yet, there have been few attempts to evaluate the 'big picture' of diversity management in Australian organisations. Here the aim is to review

* Newcastle Business School, University of Newcastle

** Faculty of Business, Queensland University of Technology

*** Griffith Business School, Griffith University 
MD in Australia, place it in its legislative context, examine the drivers for MD, discuss their relationship to legislative measures promoting equity, and examine the practice of MD. Shifting responsibility for achieving equality objectives to organisations makes sense in terms of efficiency. However, the practice of MD is itself diverse (Strachan et al 2010), and even where there is some prescription and guidance such as in the Australian EEO legislation, the outcomes are variable (Burgess et al 2007). We thus explore the rationale of MD, examine the legislation support equity in the Australian workplace and discuss some organisations that have been selected as 'best practice' exemplars in terms of their EEO reporting.

\section{What is MD?}

Managing diversity (MD) has its origins in the USA in the context of affirmative action policies and a rapidly changing workforce demographic (from white males to increasing numbers of women, Hispanics and Afro Americans). In the words of Thomas (2001), anti discrimination and affirmative action legislation had provided the 'entry tickets' into the workforce, while MD was about productively building on this entry. Kirton and Greene (2005) point out that the US context of MD is very specific to legislative, political and demographic conditions, and that MD as a business process is not necessarily transferable to EU nations. Similarly in Australia one has to be cognisant of the specific legislative and demographic context of MD policies. MD is also organisationally specific. MD is confined to those organisations that are sufficiently large to have diverse workforces and to have a HR division that is responsible for workforce management and development. MD is individualised in the sense that each organisation develops its own program subject to its own needs and those of its employees. Indeed, the programs could be individualised to satisfy the diversity needs of each employee. While programs must conform to universal legislative conditions such as anti-discrimination laws the authority for MD comes from within the organisation. In this context MD can be said to be fluid and evolving, subject to development and change as the organisation evolves in terms of its employees, business conditions, and the prevailing organisational objectives. It follows that $\mathrm{MD}$ is inexorably linked to organisational goals, and hence discussions of MD are invariably linked to the 'business case' for MD (Holterman 1995).

Diversity itself remains an unclear concept. It is contextually specific and linked to demographic and socio-political features of the population and the workforce. Diversity is a selective concept in that some but not all physical characteristics are incorporated into MD programs (Moore 1999). Diversity also has invisible and hidden aspects that include culture and attitudes (Moore, 1999). MD programs in general mimic or reflect legislative programs that prohibit discrimination and encourage EEO opportunities within the workplace, and hence many MD programs support such groups as women, ethnic minorities, older workers and people with a disability. There is a tension between diversity as a factor that generates forms of exclusion and inferior material outcomes in the labour market, and diversity as a factor that can be harnessed 
towards improving organisational performance. While diversity is embedded in worker difference and notions of equality and justice, the broader equity goals linked to MD are not necessarily the terms by which MD programs are assessed within the organisation.

$\mathrm{MD}$ offers an individual-based approach to disadvantage and is a program of self regulation by business. MD seeks to recognise, value and utilise differences between individuals rather than dilute or deny that the differences exist. Some argue that managing diversity is radically different from affirmative action (Kandola and Fullerton 1994; Thomas and Ely 1996), while others support the view that one offers an extension of another (Thomas 1991, 1996; Liff 1999). The four main characteristics that differentiate the diversity from the equality approach are that differences are viewed positively; differences attached to group membership are downplayed; the business case rather than the social justice case is predominant; and a transformation in organisational cultures is required (Kirton and Greene 2005).

\section{The Australian Legislative Context for MD}

$\mathrm{MD}$ is a voluntarist process on the part of organisations that addresses the diversity of employee needs and recognise employee difference. This voluntarist approach needs to be differentiated from legislative norms that are compulsory and may also themselves embody MD principles. In Australia there are binding regulations that address diversity, discrimination and equity issues in the workplace. The substantive legislation regarded broadly as equity legislation in Australia now totals more than twelve Federal and State Acts and incorporates two approaches, anti-discrimination and affirmative action (also known as equal opportunity). The anti-discrimination legislation, according to the Convention on the Elimination of All Forms of Discrimination Against Women 1981, has dual obligations of both prohibiting discrimination and ensuring equality of outcomes (Sex Discrimination Act, 1984). Focusing on equality of individual rights, it is concerned with redress and remedy for any breach. The affirmative action/equal opportunity legislation includes those Acts that stipulate a systematic approach to the identification and elimination of barriers that disadvantaged groups encounter in the workplace. It aims to overcome entrenched discrimination by requiring positive steps to change. It is not concerned with individual instances of discrimination (Ronalds and Pepper 2004). In the Australian private sector, the legislation focuses on women. In the Australian public sector, other groups included are; Indigenous Australians; people with a disability; and people from a non-English speaking background (French et al 2010).

Anti-discrimination legislation makes it unlawful to make discriminatory actions in the workplace based on a number of identity differences including sex, race, religion disability, age and others. Anti-Discrimination Acts in Australia identify and prohibit direct discrimination and indirect discrimination (where a requirement or condition is more likely not to be able to be complied with by members of one group and is unreasonable in the circumstances)(Ronald and Pepper 2004). According to Ronalds (1991: 10) the legislation has a 
symbolic effect as it identifies 'that there are certain actions and forms of behaviour which the majority of society no longer find acceptable'.

In Australia there are practical problems in taking an anti-discrimination case, resulting from the array of inconsistent legislation available; complexity of definitions and interpretation, including issues of coverage; exemptions and redress available (Charlesworth et al 2002). The possibility of remedy is also questionable as direct, intended discrimination is less likely to occur than discrimination that is unintended, indirect and systemic.

Affirmative action (since 1999 more commonly referred to as equal opportunity) legislation is also based on opposition to the neo-classical economic view of a free and competitive market system but in contrast to the anti-discrimination approach it seeks to move beyond individual, universal solutions and reactive methods of addressing unfair discrimination. Instead, it encourages the analysis of systemic or structural discrimination in order to design appropriate proactive remedies at an organisational level (Ronalds 1991). The recommended approach to systemic change is one based on different treatment of individuals within a collective group, in order to overcome natural or social difference (Poiner and Wills 1991).

Australia's principal affirmative action/equal opportunity legislation, the Equal Opportunity for Women in the Workplace Act 1999, was not intended to provide positive discrimination for women but to ensure that women were not disadvantaged by virtue of their sex through biased terms, conditions and entitlements in employment (Strachan and Burgess, 2001). Individual enterprises (with more than 100 employees) are responsible for the implementation of an equal opportunity/affirmative action program. The Act includes the requirement of a regular analysis of current employment statistics and workplace practices. Accountability is ensured through direct reporting to a government agency, and the penalty for non-reporting is being named in Parliament and being ineligible for federal government contracts or specified industry assistance.

Rather than being an alternative approach to anti-discrimination, Poiner and Wills (1991) suggest that affirmative action/equal opportunity is an umbrella term that includes a range of corrective responses to discrimination, past and present. Implemented through what Konrad and Linnehan (1995) determine as identity conscious structures, it requires decision makers to consider both individual merit and demographic group identity in order to remedy current discrimination; redress past injustices and achieve fair and visible representation across all positions. This occurs by monitoring personnel decisions made about members of protected groups more stringently; comparing the numbers, experiences and outcomes of protected groups with those of others and making special efforts to employ and promote the career progress of disadvantaged groups.

MD programs have to take place within this legislative context. How does MD differ from anti discrimination and EEO? First of all, MD is voluntarist, whereas legislation is compulsory for those organisations that fall within its ambit. Second, MD is potentially available to all organisations, whereas EEO 
programs only apply to those organisations employing over 100 persons. Third, whereas the legislation regulates conditions for those who are currently employed, MD programs could be linked to the engagement of groups who are currently under-represented in employment. Fourth, the scope of MD programs is extensive in terms of identified groups and organisational policies, but EEO is confined to women employees and anti discrimination provisions target a number of specific groups such as older workers, women, workers with a disability and Indigenous Australians. However, as we will demonstrate, those organisations that have been recognised for their EEO programs invariably have formal MD programs.

\section{Approaches to MD}

Two major implementation approaches for managing diversity are presented here to explore the distinctions within diversity management. One approach, named here as 'productive diversity', is based on a business case for diversity management, and the other, named here as 'valuing diversity', is based on a human resource/organisational development approach.

\section{Productive Diversity - A 'Business Case'}

Increasingly the value of managing the process of achieving equity outcomes and addressing disparity has been marketed through the business imperative. The business case claims that productivity can be increased, and competitive advantage gained, through the utilisation of the different skills of diverse individuals. The basis of this argument are the utilitarian concepts of mutual benefit (Shaw, 1995) and productive advantage (Cope and Kalantzis 1996) rather than justice.

Underlying the business case is a human capital theory approach: an advocacy of the benefits of finding a profitable or practical use for a diverse range of people and their skills, representative of society rather than exclusive of some of the minority groups within that society. The benefits to be gained from workforce diversity through the use of business networks, varied skills, cultural understandings and market knowledge are said to include include stronger corporate image, increased productivity and reduced labour turnover (Bruegel and Perrons 1995). Cope and Kalantzis (1997) argue that productive diversity is no more and no less than good business sense because in the new global environment local diversity and global interconnectedness are more critical productive factors than they ever have been. The use of family-friendly policies is also recognised as providing a means of managing for diversity that can provide economic benefits through the reduction of staff costs in turnover, sick leave, absenteeism and stress (Kramar 1995). Research shows organisations can expect to drive their own growth through managing equity and diversity opportunities to gain greater marketplace understanding, increasing creativity and innovation and effective global relationships (Robinson and Dechant 1997).

This approach to managing difference is also seen to be of value when the equal opportunity concept is difficult to 'sell' to management, or when it is new 
and untried. It is also seen as useful when resources are scarce. Arguments for the utilisation of individuals for increased productivity are seen as useful when priorities are in conflict and when there is no clear way of fulfilling everyone's needs and goals. Utilising the organisation's human resources to the best possible advantage appears to be a providential solution.

However, addressing any unfair disparity by acknowledging diversity for reasons of increased productivity has severe limitations, due in part to the fact that not all individual rights or abilities can be reduced to tangible productivity gains. Dickens (1999) suggests that the business case for equality is contingent upon the profitability of the firm and the vagaries of the product market. This becomes dangerous if and when inequality is judged as productive. If diversity policies are introduced only to support a business objective, there will be times when a homogenous workplace further sustains the business objective or worse when ambivalence results in limited improvement.

A utilitarian approach does not attempt to address current inequalities. Without recognition that the social structure itself is unequal and unjust, the possibility of achieving equality is questionable (Poiner and Wills 1991). The business case for managing diversity is acknowledged to offer a narrow approach to achieving equity. Rarely does the business case consider such inequalities as low pay, the rights of part time workers, power differentials or the sexual division of labour. Dickens (2000) thus challenges the notion that the business case for diversity can be an efficient means of achieving equal opportunity. Without legislative and social regulation, the business case cannot result in other than a constricted implementation of managing diversity: 'State intervention is central to an equality agenda because the market tends to produce discrimination, not equality' (Dickens 2000:13).

\section{Valuing Diversity}

Another perspective within the managing diversity framework involves the valuing of difference, with mutual adaptation of the individual and the organisation as a desired end result. The basic premise of this perspective for addressing workplace disparity is the accommodation of different individuals and the adaptation of organisation systems for reasons of best management practice and mutual benefit and development. It involves including everyone in the process, recognising diversity as good for business and relaxing assimilationist criteria by changing the dominant culture (Thomas 1996). Cross-cultural education including sharing, mentoring and networking is recommended as assisting individual and group change (Fine 1995). Liff (1999) notes that research indicates that the bulk of policies utilised by organisations fits closer to the 'valuing diversity' approach.

The benefits of managing disparity through this approach are said to include acknowledgement of the changes required to cultural, political and structural systems within organisations, rather than to either individuals or disadvantaged groups or both. Without substantial change to these systems, different individuals will continue to be indirectly discriminated against. This is recognised as a major deficiency of the legislated approaches that seek to force 
employees to fit pre-existing structures and practices. In addition, the 'valuing diversity' approach analyses workplace disparity issues and seeks to treat the problem, namely the structures, rather than addressing the symptoms. Liff (1999) points out that this approach looks much like the proactive end of equal opportunity (affirmative action) as it sees differences between people in terms of their treatment and experiences at work based on their social group membership. An alternative identified by Liff (1999:71) is one based on 'dissolution of difference.' The 'dissolving differences' analysis is based on the argument that there are multiple sources of difference just as important as gender and that people should not be confined by their social group membership. This view privileges individuals as the object of policy rather than social groups. Kirton and Greene (2005) argue however that there is an assumption of 'sameness' implicit in the dissolving difference approach: a view that everyone should be treated the same regardless of their group characteristics. Like the liberal equality approach, this does not lead to equal outcomes. French (2001) argues that there is little practical difference between equal and 'same' treatment of individuals, both in the anti-discrimination approach and in the neutral treatment of individuals through the managing diversity approach.

A limitation in using the valuing difference approach is that any change will be extremely slow, with no guarantee that the major changes required to workplace systems can or will actually take place. Thomas (1996) believes that an organisation may take several years to determine real needs and as long as twenty-five years to realise true change. This of course does little to assist individuals in the workplace today. Liff and Cameron (1997) suggest that where traditional equal opportunity strategies encourage a view that women have a problem and need help, managing diversity encourages the view that organisations create problems for some groups while advantaging others. Changing organisations is more difficult and more time consuming than offering extra assistance and training to a group identified as deficient. In addition the traditional equal opportunity strategies 'pass the buck' for any lack of success to the individual, who is deemed to be not only deficient but also difficult to please.

\section{Australian Experience With EEO and MD}

Using these definitions, we can now examine the approaches to EEO and MD that seem to be present in Australian organisations that have received official commendation for their EEO programs. Overall Australian case studies of EEO best practice organisations show the influential role of the business case in driving EEO and MD, especially in the context of a falling unemployment rate and the need by business to attract and retain skilled labour (in the period up until 2007). We have selected those organisations that have been identified by the Equal Opportunity in the Workplace Agency (EOWA) as being exemplars in terms of having active EEO programs. While recognising that EEO and MD programs are not identical, many of the identified organisations did report that they had active MD programs, and indeed the EEO programs were often conflated with MD. The selected case studies cover organisations that are active not only in promoting EEO within the workplace but also in linking this 
with MD within the workplace. The case studies on the EOWA website not only showcase organisations judged to have achieved EOWA's highest standards, but also gives us some insights into why organisations say they are pursuing an equity and MD agenda. The reporting here is selective, not representative, with a focus on organisations that have been recognised for meeting and going beyond $\mathrm{EEO}$ requirements.

In examining selected case studies on the EOWA website (EOWA 2009), we have selected a wide range of industries, including Coles Myer (retailing); KPMG (consulting services); General Motors (manufacturing); World Vision (charity); Connell Wagner (engineering services); Wrigleys (food manufacturing); One Care (community services); Mounties (recreation services); IGT (manufacturing); Westpac (banking) and, Henry Davis York (legal services). We examine what is said by the organisations about their programs, paying particular attention to program drivers and some of their specifics.

Many of the case study organisations discuss EEO and MD as though the terms were interchangeable: they classify all their programs under the label of diversity management, or they equate EEO program for women employees with diversity management. The reported programs adopt a range of apparently non-gendered nomenclature, but underneath these there are frequently gender specific programs. For example the retail 'giant' Coles Group has a Diversity Strategy with a Diversity Manager, but their case study highlights training programs titled Coles Myer Equal Opportunity Program; an online 'Diversity and Equal Opportunity' training program; leadership programs for women, including 'Stretching the boundaries' and 'Career Resilience for Women' (focused on 'developing the leadership and networking skills of high-potential women'); and a Women's Network and Executive Women's Network. GM Holden, vehicle manufacturer, has a 'Diversity at Holden' strategy, and a Holden Women's Council. The charity World Vision Australia has a 'People, Culture and Learning Department'.

Typical of the statements that proclaim MD include the following, by Coles: 'Our Diversity Strategy: linked to the goals, values and behaviours of the business'. The focus was determined by the desire to make Coles 'a place where people want to work' and 'an awareness that the workforce needs to reflect the diversity of both customers and the wider community' (Coles Group). KPMG, an international accounting services firm, proclaims that 'Diversity is a key area of focus for KPMG. The firm believes it is essential for business growth and innovation to encompass a broad and diverse mix of people from differing backgrounds, gender and cultures who have varying thinking styles and qualities.' The EOWA website itself proclaims that 'diversity is increasingly being melded into the culture of the organisation, thanks to a clearly defined strategy with accountability at executive level and the integration of diversity into a range of cultural programs, as well as recruitment and development' (EOWA 2009).

The EEO and MD programs of many of the organisations reflected the tight labour markets operating from 2005 to 2007 in particular industries and occupations (EOWA 2009). In some cases, the shortage of skilled labour and the desire to attract and retain labour over the previous economic boom, especially 
women's labour, propelled organisations to develop an equity/diversity strategy. The consulting engineering firm Connell Wagner identified 'an ongoing perception within the industry that consulting engineering is difficult and demanding, resulting in it being more challenging to recruit and attract engineering graduates (in particular women graduates) into the industry. General Motors Holden expressed 'the very clear need to gain greater access to the talent pool..., as well as the importance of attracting and retaining more women, particularly into non-traditional roles such as engineering. The law firm Henry Davis York reported that 'competition between law firms was, and remains, intense and HDY needed not only to attract new recruits but also retain them and where appropriate, promote them within the firm. World Vision Australia and the consumer goods manufacturer Wrigley's wanted to attract a wider pool of applicants. Wrigley's expressed a common issue: attracting and retaining the best person for the job chas not been easy and the company has recognised a need to address the growing shortage of skilled workers within the labour market by adopting more creative solutions to its job design and selection criteria. OneCare, a community services organisation of 506 employees, operated in the highly competitive nursing sector: 'Labour market forces in professional health dictate that we, as an organisation, need to seek market advantage to attract and retain staff, particularly Registered Nurses.' At the same time, 'Diversity is supported within our organisation and we value the contribution that gender, cultural and religious diversity can make to our organisation and our customers' (EOWA 2009).

The organisations judged as 'best practice' tended to integrate MD with standard human resource management functions such as recruitment and selection procedures, and particularly the instigation or expansion of flexible work arrangements. For example, IGT, a firm of 250 employees that develops and manufactures entertainment games, was committed to providing 'a flexible, family-friendly and balanced environment which allows IGT to recruit and retain the best employees. IGT's philosophy is that is our employees understand that we have a vested interest in their personal growth, career development and their life outside of work, that their loyalty and productivity will be of a consistently high standard within the organisations.. In addition, the majority of EOWA case study organisations (10 out of 15) specifically identified the low numbers of women in senior management as a factor driving their MD programs. From these case studies we can observe the appeal to good corporate citizenship through the promotion of equity principles coupled with the reality of an increasingly feminised workforce and a tight labour market.

All the large organisations (those with over 4,000 employees) specifically linked MD strategy with overall business goals. Coles Group Diversity Strategy 'was determined by the desire to make Coles a place where people want to work and an awareness that the workforce needs to reflect the diversity of both customers and the wider community'. The outcome was that 'diversity is increasingly being melded into the culture of the organisation, thanks to a clearly defined strategy with accountability at executive level and the integration of diversity into a range of cultural programs, as well as recruitment and develop- 
ment. Westpac, a bank with more than 22,000 employees, explained that 'attracting, retaining and, importantly, advancing women helps us deliver against our strategic objectives for our employees, our customers, our shareholders and for the community.' The CEO said 'It's not a compliance issue; it's not a diversity issue, and it's not a social responsibility issue. Yes, it's the right thing to do, but it's also the strategic thing to do for Westpac.'

All but two of the smaller organisations also made the link with organisational strategy. Henry Davis York 'developed and implemented an extensive 'people focus' strategy linked to the goals and values of the firm.' In World Vision Australia the initiatives were driven by the People, Culture and Learning Department which assisted business units 'to develop appropriate practices for managing and retaining staff'. All organisations framed their programs within an organisational business case. Most quantified savings to the organisation in some way, citing more female recruitment, increased retention and higher return rates from maternity leave. GM Holden had increased its paid maternity leave from 6 weeks to 14 weeks after two years service. This and flexible working options such as part-time work and job sharing had increased the return rate of women from 67 per cent to 92 per cent. Henry Davis York had achieved a 100 per cent return rate with similar strategies and had reduced recruitment costs through internal recruitment, a strategy also successfully used by other organisations. Mounties, a community recreation club, said they had the "highest profit in the industry, best safety record, lowest staff turnover rates and lowest absenteeism rates' (EOWA 2009).

At one level then, MD and EEO represent a form of public relations and can be placed within the context of good corporate citizenship. Large organisations are expected to enshrine basic principles such as equality and to embrace anti discrimination in the workplace and $\mathrm{MD}$ gives substance to these principles. At another level MD reflects the realities of a changing workforce composition: just as Thomas (2001) noted in the USA, the reality is that the Australian workforce is becoming more feminised, older and with growing numbers of immigrant workers from non European origins (Sappey et al 2006, ch.3). Up until 2008, and in the context of a tight labour market and a very diverse labour supply, embracing MD reflects the shift away from the traditional norms and composition of the labour supply that was prevalent in previous eras (Watson et al 2003). MD enables organisations to build upon the legislative base and develop programs that are innovative and attractive for employees, especially where there are labour shortages or high labour turnover. For example, programs that address work and family balance can enable organisations to retain valued employees (Sappey at el. 2006, ch.3).

It is apparent that the formal EEO programs listed on the EOWA website serve as a demonstration for organisations as to what can be done to attract and retain not only women staff but also staff from other groups who may be disadvantaged or marginalised in the labour force. This becomes an important issue in periods of tight labour markets. The nature of EEO programs and the best practice guides and examples used by the EOWA demonstrate to organisations not only how an EEO program can be developed and implemented for 
women employees, but how such programs could be used for other workforce groups. Hence we find that EEO and MD programs are reported side by side in many organisations.

At another level the rise of MD and formal EEO programs is also linked to the rise of human resource management (HRM) programs and strategic HRM within large organisations. MD programs originate within organisations, are managed by organisations and are linked to organisational goals. MD programs are directed by management and stress individual difference. This gives a strategic edge to MD programs and links MD to organisational performance. However, the HRM driver is not without its limitations, especially if the HR programs are of the 'hard' variety where cost and efficiency goals take precedence over equity objectives (Kirton and Greene 2005, ch.9). Here there is a gulf between the claims of MD and EEO, and the outcomes.

In their organisational case studies of EEO programs in the workplace, Burgess et al (2007) found that there was a gap between the official organisational statements surrounding MD and EEO and actual workplace practice. Specifically in the case of women employees who sought programs to facilitate work and family balance, many workplace initiatives were blocked by line managers, the pressures of production schedules or ignorance. Few EEO programs were converted into industrial instruments (workplace agreements), and in the main, trade unions did not see these issues (especially flexible working arrangements) as priorities in the bargaining round. In many of the case studies female workers depended upon informal arrangements to manage work and family responsibilities. They found that having an organisational EEO program and workplace agreement was no guarantee that work and family measures will be introduced at the workplace. Legislated minimum standards that protect workers against overt discrimination and harassment effectively motivate companies, but only in establishing a baseline. Neither the industrial agreements accessed, nor the reports to EOWA, offered more than token acknowledgement of work and family issues. Some organisations embraced more elaborate or sophisticated ways of enticing workers or retaining them. This was largely in response to labour market forces, such as a shortage of workers with the appropriate skills, or the costs to business of losing highly trained personnel, which are important determinants of workplace policies and practices (Burgess et al 2007).

The experience with MD and EEO is patchy. Some organisations are better than others in terms of translating intentions into practice. Here we have only reported on those organisations that are regarded as exemplars in terms of EEO programs, many of which are linked to MD programs. Within this context there is an obvious business case supporting the programs. While the EOWA provides examples of best practice organisations, there is limited auditing of the organisational processes and outcomes. As the labour market has tightened many organisations have become more conscious of the need to attract and retain quality labour, and this is undoubtedly a major factor driving $\mathrm{MD}$ and EEO programs. Burgess et al (2007: 430) conclude that 'The EEO and workplace bargaining regime are both very dependent on the "business case" for family friendly employment measures, one which is supported by Government and its 
agencies (for example EOWA) but is in tension with other ideas based on arguments from equity and social justice'. In turn this means that such measures are unevenly distributed within and across workplaces and that development and implementation becomes very dependent upon managerial prerogative. While businesses may deploy 'flexible' employment arrangements these are not necessarily compatible with integrating work and family responsibilities.

Here we have the nub of the problem: the norms of the business case are not those of underlying equity principles that support MD and EEO. The business case assumes convergence; this is not always the case. In addition, sustaining MD becomes difficult where business conditions are changing, it seems that strong economic growth fits within the business case MD agenda, but what happens now that these conditions have altered world wide? The fragility of the business case can be seen in comments such as 'KPMG built a business case for diversity focusing on the labour shortage phenomena which had become a reality for the firm' (EOWA 2009).

\section{Conclusions}

In Australia, organisations are largely left to make their own judgements about what is equitable for employees and profitable for the business. It is not surprising that organisations are really only certain about what to do when policies are clearly spelt out in legislation (Liff 1997; Strachan et al 2004). Australia has a mix of legislated standards and voluntary codes that support EEO in the workplace. The EEO regime is largely a reporting one. From the 1980s the main concern was with directly addressing discrimination in the workplace and later with promoting EEO for women employees. Over the past decade the emphasis has shifted more towards corporate responsibility and organisations doing the right thing in terms of broader equity objectives. This voluntarism has been boosted by the tightening labour market that puts pressure on organisations to acknowledge and address the diversity of their workforce. As Burgess al (2007: 535-36) comment:

Organisations are able to choose the policies and practices that they believe are appropriate to their particular business situations, and the extent to which they will implement them. This might include; attention to workers' preferences in relation to individual work arrangements and career paths; emphasis on recruiting and/or training women in non-traditional roles; increasing 'flexibility' in the span of hours worked, length of shifts and other temporal arrangements; or any one of a number of other priorities. Organisations can portray many different policies and practices as related to EEO without assessing outcomes against specified criteria or undertaking any measurement of change. Organisational equity policies and practices are determined by ad hoc business and labour force demands which may be coloured by the organisation's own ethics and values.

Subtle forms of discrimination continue somewhat insidiously in organisations with systems and practices that seemingly fulfil equal opportunity prescriptions 
or anti-discrimination legislation or managing diversity recommendations, yet with outcomes that continue to demonstrate that people remain unfairly disadvantaged, based on unrelated and unalterable attributes or characteristics (Burgess et al 2007). Neither anti-discrimination, affirmative action, equal opportunity, nor managing diversity, offers a cure-all for the inequality many people experience in the workplace. The different approaches to managing individual and collective 'sameness' and 'difference' and any related disparity at work result in different structures and different policies for implementation. Even within the same industry and in the same labour market, organisations can have very different approaches and programs towards EEO (Burgess et al 2010). These different structures and policies are predictive of different outcomes on many of the measures of employment of individuals. We argue that effective equity management that brings substantive change to unfair workplace disparity is not a 'one size fits all' model. It needs to be an individually tailored model that encourages strategic change and which involves analysis of specific contextual issues in addition to analysis of current structures and systems. Yet, little is known of the factors of influence on management choice in determining their organisation's stance. Further, real change requires analysis of social issues including the 'male stereotype' as the dominant work model. Changes in state provisions and organisation structures and practices are required but these often lag behind the need for real change.

While considerable research continues in the area of workplace disparity and difference at an individual and collective level, there has been little research focusing on the strategic implementation of policies designed to address disparity and more importantly the related outcomes, in order to develop models of excellence. The EOWA case studies present only a small sample of organisations that formally meet and go beyond EEO guidelines. The case studies demonstrate the important demonstration and experiential effects of formal EEO programs in being extended into broader MD measures that take in a range of different groups in the workforce. It continues to be vital to ponder the issues, explore and probe new ideas thoroughly and to fully comprehend the intricacies of social and individual inequity if there is any hope of redress. Despite the exploratory nature of equity at work, many organisations continue to explore the means of achieving it. The use of various approaches including a range of structures and policies for implementing equity management is increasingly being reported, not only through the EOWA but through various public reporting and awards systems and on organisational web sites. Liff (1999) notes that those organisations receiving awards in Britain for their opportunity policies are those that are implementing side-by-side policies that show positive action with those that present a more radical challenge for organisation culture and practice. In fact, the multiple implementation of different equity management strategies is increasingly recommended (Sheridan 1998; Liff 1999; Dickens 2000; French 2005). This point comes through in the organisations reported on from the EOWA website. However, against these activist equity programs, at the other end more than ten per cent of organisations are doing nothing and 
approximately half the reporting organisations are undertaking a minimalist approach towards equity programs (French 2001).

MD programs will remain patchy in terms of their application and outcomes since they are voluntarist and only have the legislative norms that are set through EEO and anti discrimination legislation (French et al 2010). As is the case with $\mathrm{EEO}, \mathrm{MD}$ programs rarely make their way into workplace agreements (Burgess et al 2007). One way to strengthen MD would be to strengthen EEO requirements across disadvantaged groups and strengthen the application of EEO through such practices as the auditing of programs (Strachan et al 2007).

\section{References}

Bruegel, I. and Perrons, D. (1995) 'Where do the costs of unequal treatment for women fall? An Analysis of the incidence of the costs of unequal pay and sex discrimination in the UK', in J. Humphries and J. Rubery (eds) The Economics of Equal Opportunities, Equal Opportunities Commission, Manchester, pp. 55175.

Burgess, J., L. Henderson and G. Strachan (2007) 'Work and family balance through equal employment opportunity programs and agreement making in Australia', Employee Relations, 29 (4), pp. 415-431.

Burgess, J., Henderson, L. and Strachan, G. (2010) 'Organisations do it differently: Case studies in male-dominated industrial manufacturing', in G. Strachan, E. French and J. Burgess, Managing Diversity in Australia: Theory and Practice. McGraw Hill, Sydney, forthcoming.

Charlesworth, S., Campbell, I. and Probert, B. with Allan, J., and Morgan, L. (2002) Balancing work and family responsibilities: Policy implementation options, Report for the Victorian Departments of Premier and Cabinet and Innovation, Industry and Regional Development, Centre for Applied Social Research, RMIT University, Melbourne.

Cope, B. and Kalantzis, M. (1996) Productive Diversity A New Australian Model for Work and Management, Pluto Press, Annandale.

Cope, B. and Kalantzis, M. (1997) Productive diversity: Management lessons from Australian companies, Occasional Paper no. 20, Centre for Workplace Communication and Culture, Sydney.

Dickens, L. (1999) 'Beyond the business case: A three-pronged approach to equality action', Human Resource Management Journal, 9 (1), pp. 9-19.

Dickens, L. (2000) 'Promoting gender equity at work: A potential role for trade union action', Human Resource Interdisciplinary Gender Studies, 5 (2), pp. 27-45.

EOWA (2009) (Equal Opportunity for Women Agency) Case studies, available: http://www.eowa.gov.au/Case_Studies.asp [accessed 28 April 2009].

Fine, M. G. (1995) Differences in the Workplace: A Theoretical Perspective in Building Successful Multicultural Organisations: Challenges and Opportunities, Quorum Books, London.

French, E. (2001) 'Approaches to equity management and their relationship to women in management', British Journal of Management, 12 (4), pp. 267-285. 
French, E. (2005) 'Strategic change has an integral role in effective equity management: No one size fits all model', Strategic Change Journal, 14 (1), pp. 35-44.

French, E., Strachan, G. and Burgess, J. (2010) 'The theoretical and policy context for diversity: Conflicting beliefs and competing ideals' in G. Strachan, E. French and J. Burgess (eds) Managing Diversity in Australia: Theory and Practice, McGraw Hill, Sydney, forthcoming.

Holterman, S. (1995) 'The costs and benefits of British employers of measures to promote equality of opportunity' in J. Humphries and J. Rubery (eds) The Economics of Equal Opportunities, Equal Opportunities Commission, Manchester, pp. 137-145.

Kandola, R. and Fullerton, J. (1994) Managing the Mosaic: Diversity in Action, Institute of Personnel and Development (IPD), London.

Kirton, G. and Greene, A. (2005) The Dynamics of Managing Diversity: a Critical Approach. $2^{\text {nd }}$ edition, Elsevier, Amsterdam.

Konrad, A. M. and Linnehan, F. (1995) 'Formalized HRM structures: Coordinating equal employment opportunity or concealing organisational practices?', Academy of Management Journal, 18 (3), pp. 787-820.

Kramar, R. (1995) 'Equal employment opportunity: An essential and integral part of good human resource management', Australian Human Resources Management: Current Trends in Management Practice, pp. 223-241.

Liff, S. (1997) 'Two routes to managing diversity: Individual differences or social group characteristics', Employee Relations, 19 (1), pp. 11-26.

Liff, S. (1999) 'Diversity and equal opportunities: Room for a constructive compromise?', Human Resource Management Journal, 9 (1), pp. 65-75.

Liff, S. and I. Cameron (1997) 'Changing equality cultures to move beyond "women's problems"', Gender, Work and Organization, 4 (1), pp. 35-46.

Moore, S. (1999) 'Understanding and managing diversity among groups at work: Key issues for organisational training and development', Journal of European Industrial Training, 23 (4/5), pp. 208-217.

Poiner, G. and Wills, S. (1991) The Gifthorse: A Critical look at Equal Employment Opportunity in Australia, Allen and Unwin, Sydney.

Robinson, G. and Dechant, K. (1997) 'Building a business case for diversity', Academy of Management Executive, 11 (3), pp. 21-31.

Ronalds, C. (1991) Affirmative Action and Sex Discrimination: A Handbook on Legal Rights for Women, Pluto Press, Sydney.

Ronalds, C. and Pepper, R. (2004) Discrimination Law and Practice, $2^{\text {nd }}$ edition, Federation Press, Sydney.

Sappey, R., Burgess, J., Lyons, M. and Buultjens, J. (2006) Industrial Relations in Australia, Pearson Education, Sydney.

Shaw, J. (1995) Cultural Diversity at Work - Utilising a Unique Australian Resource, Business and Professional Publishing, Sydney.

Sheridan, A. (1998) 'Patterns in the policies: Affirmative action in Australia', Women in Management, 13 (7), pp. 243-252. 
Strachan, G. and Burgess J. (2001) Affirmative action legislation in Australia - the legislative model, paper presented at Rethinking Gender, Work and Organisation Conference, Keele University, UK, 27-29 June.

Strachan, G., Burgess, J., and Sullivan, A. (2004) 'Affirmative action or managing diversity - what is the future of equal opportunity policies in organisations', Women in Management Review, 19 (4), pp. 196-204.

Strachan, G., French, E. and Burgess, J. (2010) 'Approaches to equity and diversity in Australia: The national and international context' in G. Strachan, E. French and J. Burgess (eds) Managing Diversity in Australia: Theory and Practice, McGraw Hill, Sydney, forthcoming.

Thomas, D. A. and Ely, R. J. (1996) 'Making differences matter: A new paradigm for managing diversity', Harvard Business Review, September-October, pp. 79-90.

Thomas, R. (1991) Beyond Race and Gender: Unleashing the Power of Your Total Work Force by Managing Diversity, American Management Association, New York.

Thomas, R. (1996) Redefining Diversity, American Management Association, New York.

Thomas, R. (2001) 'From affirmative action to affirming diversity', in Harvard Business Review on Managing Diversity, pp. 1-32. 